[Agr. Biol. Chem., Vol. 36, No. 9, p. 1571 1579, 1972]

\title{
Reaction of 5-Carboxypyrimidine Derivatives with Sodium Bisulfite
}

\author{
A Facile Decarboxylation Method ${ }^{11}$
}

\author{
By Kiyoshi Isono, ${ }^{2}$ Saburo SuzukI, Michio Tanaka, ${ }^{*}$ Takeo Nanbata* \\ and Kunitoyo SHibuYA* \\ The Institute of Physical and Chemical \\ Research, Wako-shi, Saitama \\ *Kaken Chemical Co., Ltd., Honkomagome, \\ Bunkyo-ku, Tokyo \\ Received January 17, 1972
}

\begin{abstract}
5-Carboxyuracil derivatives were shown to react with aqueous sodium bisulfite in mild condition resulting in facile decarboxylation to give corresponding 5-decarboxy-5,6-dihydrouracil-6-sulfonates and uracils in good yield. The former compounds were quantitatively transformed to the latter in alkaline condition. Mechanistic feature of this reaction was discussed, which implied the initial nucleophilic addition of bisulfite across the 5,6-double bond. 5-Carboxycytosine was also shown to react similarly, however, accompanied by hydrolytic deamination.
\end{abstract}

Although there are many precedents on the susceptibility of uracil and cytosine derivatives to nucleophilic attack at the 5,6-double bond, ${ }^{3-11)}$ it is just recent that bisulfite has received attention as an important uncleophile to react with uracil and cytosine. After our preliminary note ${ }^{12,13)}$ on the titled reaction has been published, papers by two independent groups (Shapiro and Hayatsu) have appeared involving the reaction of bisulfite addition on uracil and cytosine derivatives, ${ }^{14)}$ deamination $^{14)}$ and transamination ${ }^{15}$ of cytosine derivatives, and oxygene mediated reaction between 4-thiouracil derivatives and sulfite. ${ }^{16}$ These reactions all implied the addition of bisulfite to the 6-position of uracil or cytosine derivatives as the key intermediates. In this paper, we wish to describe the detailed experimental results and mechanistic feature of the bisulfite catalyzed facile decarboxylation of 5-carboxyuracil derivatives which proceeds also through the intermediate 6-addition com- pounds. 5-Carboxycytosine has also shown to react similarly with bisulfite but accompanied by deamination.

In the course of the study on chemical modification of nucleoside peptide antibiotics, polyoxins, ${ }^{13 a}$ ! we have come aware of susceptibility of polyoxins $\mathrm{D}, \mathrm{E}$ and $\mathrm{F}$ which bear 5-carboxyuracil as their nucleobase toward sodium borohydride reduction as followed by disappearance of UV absorption at $276 \mathrm{~m} \mu$. with concomitant depression of biological acitivity. Cerutti et al. has shown that uracils are susceptible to borohydride reduction in the presence of UV light. ${ }^{17)}$ Indeed, in neutral buffer solution, other polyoxins which bear uracil, hydroxymethyluracil or thymine as their chromophore resisted to borohydride reduction unless UV light was present. Thus it was considered that polyoxins of 5-carboxyuracil type suffered hydride ion attack at the C-6 position. 5-Carboxyuracils may be expected to have enhanced reactivity at the 5,6- 
double bond to nucleophile owing to the electron-withdrawing 5-carboxy group. Similar enhanced reactivity of 5-halogenouracil ${ }^{8,18)}$ or 5-nitrouracil ${ }^{19)}$ derivatives accommodated a number of useful synthetic transformations. This behavior of polyoxins of 5-carboxyuracil type prompted us to examine reactions with various nucleophiles. Among the reagent tested, sodium bisulfite was found to exert the marked change to the UV and the biological activity of polyoxins D, E, and F. For instance, when an aqueous solution of polyoxin $D$ was added with 2 to 3 equivalents of sodium bisulfite, gradual decrease of UV absorption was observed. After several hours at $50^{\circ} \mathrm{C}$, the absorbancy fell down to about one-third of the initial and considerable hypsochromic shift from $276 \mathrm{~m} \mu$ to $262 \mathrm{~m} \mu$ was observed. Change in biological activity was also remarkable; the activity against Pellictraria sasakii decreased one-thirtieth of the initial, whereas the activity against Alternaria mali increased nearly twenty times.

The reaction was found to be dependent upon the concentration of sodium bisulfite. The reaction was nearly completed after $24 \mathrm{hr}$ at $50^{\circ} \mathrm{C}$ in $0.04 \sim 0.06 \mathrm{M}$ sodium bisulfite solution, with initial $\mathrm{pH}$ of 4.4 , however, in $0.02 \mathrm{M}$ solution the reaction proceeded less than half in the same condition on the basis of UV extinction decrease at $276 \mathrm{~m} \mu$ (Fig. 1). The effect of initial $\mathrm{pH}$ was found to be more remarkable. As shown in Fig. 2, decrease in extinction at $276 \mathrm{~m} \mu$ depends highly upon the initial $\mathrm{pH}$. The lowest $\mathrm{pH}(\mathrm{pH} \mathrm{4.0*)}$ was found to be most favorable, whereas no decrease was observed at $\mathrm{pH} 7.8$. The temperature dependency of this reaction is also included in Fig. 2.

To elucidate this reaction, we first pick up polyoxin $C$ acid ${ }^{13 a)}$ [1-(5-amino-5-deoxy- $\beta$ $D$-allofuranosyluronic acid) uracil-5-carboxylic

\footnotetext{
* Below this $\mathrm{pH}, \mathrm{SO}_{2}$ gas may be evolved.
}

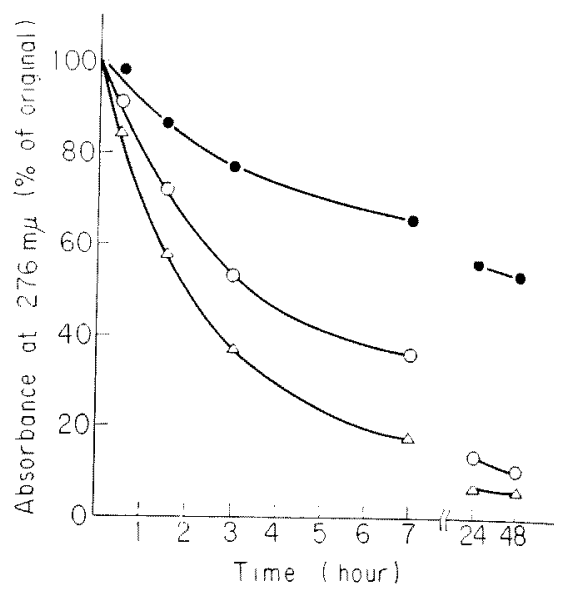

FIG. 1. Time Course of Reaction of Polyoxin D with $\mathrm{NaHSO}_{3}$.

An aqueous solution of polyoxin D $(200 \mathrm{mg} / \mathrm{ml})$ was added with:

- - $\mathrm{NaHSO}_{3} 40 \mathrm{mg}$ in $10 \mathrm{ml}$ of water; final concentration $0.02 \mathrm{M}$, molar ratio $\left(\mathrm{NaHSO}_{3} /\right.$ polyoxin $\mathrm{D})=1$.

- $-\mathrm{NaHSO}_{3} 80 \mathrm{mg}$ in $10 \mathrm{ml}$ of water: final concentration $0.04 \mathrm{M}$, molar ratio $=2$.

$\triangle-\triangle \mathrm{NaHSO}_{3} 120 \mathrm{mg}$ in $10 \mathrm{ml}$ of water: final concentration $0.06 \mathrm{M}$, molar ratio $=3$.

Initial $\mathrm{pH}$ was adjusted to 4.4 and allowed to react in a $50^{\circ} \mathrm{C}$ bath.

acid] (la) a basic nucleoside common to polyoxins $\mathrm{D}, \mathrm{E}$, and $\mathrm{F}$. Thus $1 a$ was treated with 2.2 equivalent of sodium bisulfite (initial $\mathrm{pH}$ was adjusted to $\mathrm{pH} 4.0$ and final bisulfite concentration was approximately $0.2 \mathrm{M}$ ) at $50^{\circ} \mathrm{C}$ for $16 \mathrm{hr}$. Paper electrophoretic survey of the reaction mixture revealed two reaction products. Thus, there was observed that one, UV absorbing, ninhydrin positive spot near the base line, and another ninhydrin positive anode migrating spot which lacked absorption under UV lamp., whereas no appreciable starting material la. The reaction solution was subjected to carbon chromatography. From the fraction eluted by water, ninhydrin positive UV-lacking acid (2a) was obtained as colorless amorphous powder after precipitation from water-ethanol-ether. Successive elution with $30 \%$ aqueous acetone afforded 


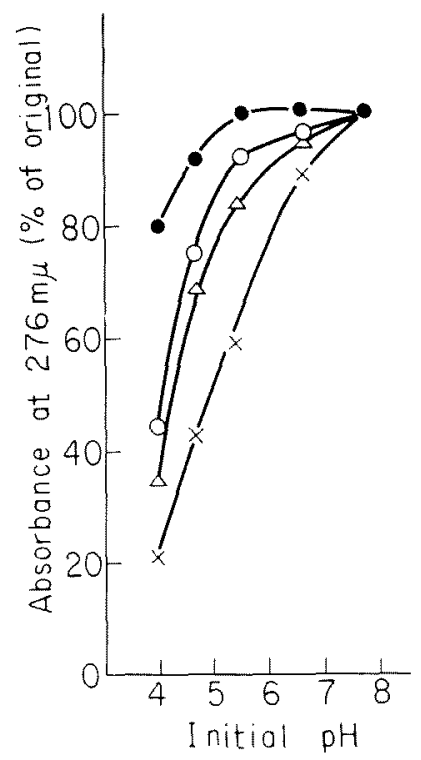

FfG. 2. $\mathrm{pH}$ and Temperature Dependency of Reaction of Polyoxin D with $\mathrm{NaHSO}_{3}$.

An aqueous solution of polyoxin D $(200 \mathrm{mg} / \mathrm{ml})$ was added with $\mathrm{NaHSO}_{3} 80 \mathrm{mg}$ in $10 \mathrm{ml}$ of water. After adjusting $\mathrm{pH}$, reaction was conducted for $22 \mathrm{hr}$ at the following temperature; $-5^{\circ} \mathrm{C}$, $\mathrm{O}-\mathrm{O} 28^{\circ} \mathrm{C}, \triangle-\triangle 38^{\circ} \mathrm{C}, \mathrm{x}-\times 50^{\circ} \mathrm{C}$.

ninhydrin positive, UV absorbing fraction, from which crystalline $3 a$ was obtained. Unexpectedly, this compound was found to be identical with uracil-polyoxin $\mathrm{C}_{,}{ }^{130)}$ 1-(5-amino-5deoxy-p-D-allofuranosyluronic acid)uracil, the decarboxylated substance of $I a$. Compound $2 a$ had the empirical formula corresponding to $\mathrm{C}_{10} \mathrm{H}_{15} \mathrm{~N}_{3} \mathrm{O}_{12} \mathrm{~S}$, and exhibited $[\alpha]_{\mathrm{D}}^{25}=-16.2^{\circ}$ in water. Infrared spectrum of $2 a$ showed a set of absorption bands characteristic to sulfonate group ( $\nu$ as $\mathrm{SO}_{2}$ at 1245 , vS $\mathrm{SO}_{2}$ at 1050 , and $\nu_{s-0}$ at $\left.625 \mathrm{~cm}^{-1}\right)$. The possibility of unstable sulfite ester may not be rigorously excluded from this data, but the stable sulfonate structure may be assigned most reasonably in analogy with all the bisulfite adducts hither to described* (vide infra $a^{20,21 j}$ ). The

* Hayatsu et al. concluded the sulfonate structure for their uracil-bisulfite adduct on the basis of Raman spectrum of the triethylammonium salt. ${ }^{120}$ possibility of the sulfite ester structure for the intermediate step will be discussed later. UV spectra of this compound was strongly suggestive for the assigned 5-decarboxy-5,6dihydro-6-sulfonate structure. As shown in Fig. 3, it exhibited only end absorption,

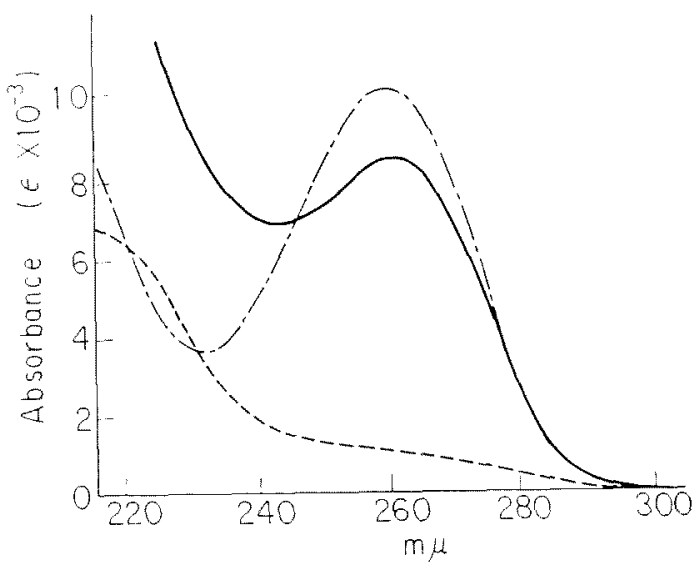

FIG. 3. UV Spectra of $2 a$.

in $0.05 \mathrm{~N} \mathrm{NaOH}$ (after $1 \mathrm{hr}$ at room temperature), - - in $0.05 \mathrm{~N} \mathrm{HCl} \ldots \cdots$ in $0.05 \mathrm{NHCl}$ after standing for $1 \mathrm{hr}$ at room temperature in $0.05 \mathrm{~N} \mathrm{NaOH}$

whereas in alkali it showed a spectrum which was identical with that of $3 a$. This change was not reversible, i.e., on subsequent acidification it gave a spectrum identical to that of $3 a$ in acid, undissociated form of 1-substituted uracil. Indeed, it was shown that $2 a$ was transformed quantitatively to $3 a$ on standing in alkaline solution ( $\mathrm{pH}$ 12) for 1 hour at room temperature. The product, after neutralization with acid, was adsorbed on carbon column and eluted with aqueous acetone. On crystallization from water, colorless crystals were obtained which was identical with $3 a$ on the basis of IR spectrum and optical rotation.

Although compound $2 a$ behaved as a single spot on TLC with several solvent systems, appearance of the anomeric proton as quartet in NMR spectrum indicated it to be a $1: 1$ 
mixture consisted of closely interrelated two compounds. Indeed, when every fractions from Avicel chromatography employing butanol-acetic acid-water as solvent, were monitored with NMR and optical rotation, each fraction showed suscessively changing NMR spectrum and rotation value. The spectra of the first fraction $\left([\alpha]_{5}^{25}=-32.8^{\circ}\right)$ and the last fraction $\left([\alpha]_{D}^{25}=+11.0^{\circ}\right)$ were seemed to be free from each other and pure enough for structure assignment. As shown in Fig. 4, the spectrum of each fraction exhibited a typical ABX systems beside the assignable doublet due to anomeric proton, suggestive for the 5-decarboxy-5,6-dihydro-6-sulfonate structure. Considerable up-field shift of each anomeric proton ( $\delta 5.35$ and 5.28) may be ascribed to anisotropy of the adjacent 6-sulfonate group.

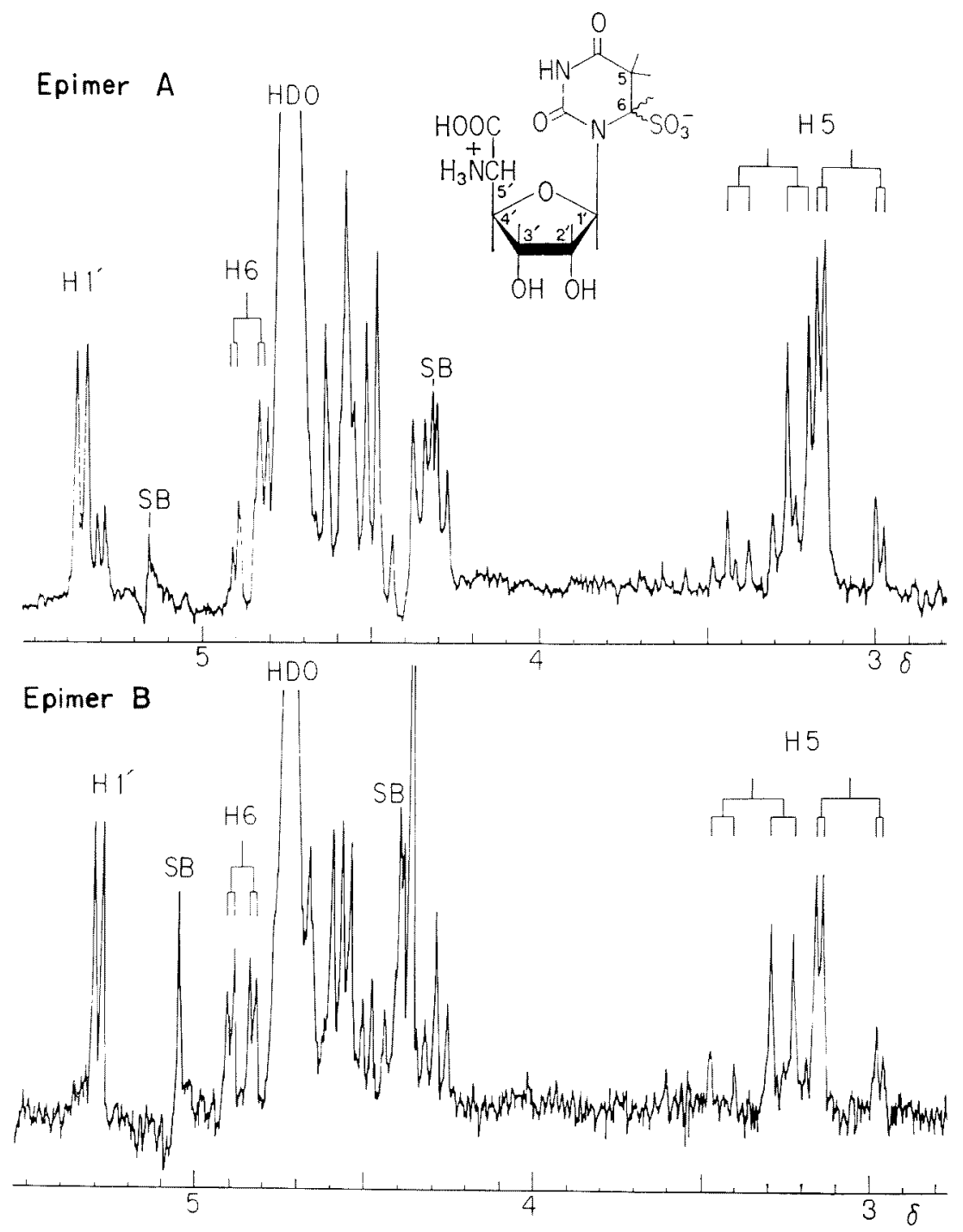

Frg. 4. NMR Spectra of Epimeric $2 a(100 \mathrm{MHz})$. 
Thus it became clear that these two compounds are epimers at the $\mathrm{C}-6$ position. However, no data are available to assign the absolute configuration to each epimer. Elimination of 6-sulfonate group in alkaline condition may reasonably result in the formation of an uracil ring.

5-Carboxyuracil ( $1 b$ ) and 5-carboxy-2-thiouracil $(1 c)$ reacted similarly with sodium bisulfite affording corresponding 5-decarboxy-5,6-dihydro-6-sulfonates $(2 b, 2 c)$ as well as uracil $(3 b)$ and 2-thiouracil ( $3 c$ ) respectively. Compounds $2 b$ and $2 c$ were obtained as crystalline sodium salt in the hydrated form with the formula corresponding to $\mathrm{C}_{4} \mathrm{H}_{7} \mathrm{~N}_{2} \mathrm{O}_{6} \mathrm{SNa}$ and $\mathrm{C}_{4} \mathrm{H}_{7} \mathrm{~N}_{2} \mathrm{O}_{5}-$ $\mathrm{S}_{2} \mathrm{Na}$ respectively. Both compounds exhibited typical $\mathrm{ABX}$ pattern ascribable to the $\mathrm{C}-5$ methylene and $\mathrm{C}-6$ methine protons. NMR spectrum of pyridinium salt of $2 b$ in DMSO$d_{6}$ showed $\mathrm{H}$ on $\mathrm{N}-1$ ( $\delta 8.97$ doublet, $J_{1,0}=$ $5.5 \mathrm{~Hz}$ ) and $\mathrm{H}$ on $\mathrm{N}-3$ ( 09.86 singlet). The former was proved to be coupled with $\mathrm{H}-6$ (03.91, multiplet) by spin decoupling experiment. This is the direct support of the C-6 sulfonate structure. Similar NMR was obtained with pyridinium salt of $2 \mathrm{C}$ in DMSO$d_{6}\left(\mathrm{H}\right.$ on $\mathrm{N}-1 ; \delta 9.72$ doublet, $J_{1,6}=4.5 \mathrm{~Hz}$. $\mathrm{H}$ on $\mathrm{N}-3 ; \dot{\partial} 10.77$ singlet. $\mathrm{H}-6 ; \dot{o} 4.02$ multiplet). Alkaline treatment of each compound resulted in quantitative formation of uracil ( $3 b$ ) and 2-thiouracil (3c) respectively.

Mechanistic feature of this reaction was illustrated in Chart 1. It is now clear from the above data that the initial step of this reaction is the nucleophilic attack of bisulfite at C-6. The intermediate carboxy sulfonate thus formed may be considered to be unstable because of the electron-withdrawing sulfonate group, resulting in facile decarboxylation to give 5-decarboxy-5,6-dihydro-6-sulfonate (2). If the reaction proceed with concerted desulfonation, uracils may be directly formed. Although we have no data why the reaction proceed in these two ways, it seems quite reasonable that bisulfite addition at the initial stage may result in the formation of the transient sulfite ester type adduct (A), which would then rearrange into the sulfonate form (B). This rearrangement may compete with the concerted decarboxylation. Once the rearrangement occured, the resulting sulfonate would not be involved in the concerted elimination leading to the 5-decarboxy-5,6dihydro-6-sulfonate, which may undergo elimination only in alkaline condition. Thus, the transient carbonium ion at $\mathrm{C}-6$ underwent the competitive attack of lone pair on the sulphur atom and decarboxylation-induced C-5 carbanion. A part of 2 may be derived from reversible addition of bisulfite (vide

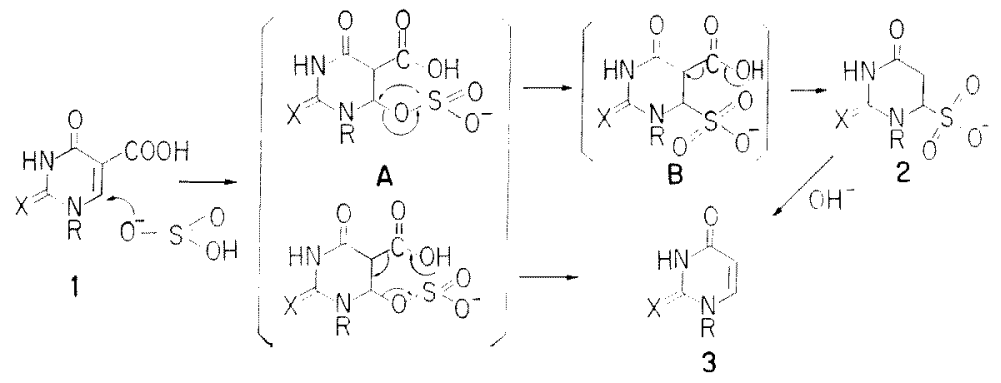

Chart 1.

a $\quad R=5$-Amino-5-deoxy- $\beta$-D-allofuranosyluronic acid, $X=O$

b $\mathrm{R}=\mathrm{H}, \mathrm{X}=\mathrm{O}$

c $\mathrm{R}=\mathrm{H}, \mathrm{X}=\mathrm{S}$ 
infra) to the formed uracils in equilibrium reaction $2 \rightleftarrows 3$, however, in this reaction condition $\left(\sim 0.25 \mathrm{M} \mathrm{NaHSO}\right.$, pH $\left.4.0,50^{\circ}\right)$, the equilibrium was shown to be much in favor of 3 and only small amount of 2 was formed. To our knowledge, there is no precedent on the mechanism of bisulfite addition, although the sulfonate structure is generally accepted for the carbonyl adducts on the basis of chemical $^{20)}$ and spectrometric ${ }^{21)}$ evidence. This reaction may be to suggest the possibility of sulfite ester type addition as an initial mode of addition of bisulfite. larger amount than uracil $(\mathrm{C}: \mathrm{U}=4: 1)$ may suggest the concerted decarboxylation-desulfonation proceeds faster than the hydrolytic deamination( Chart 2).

It is to be noted that our reaction proceeds at much lower concentration of bisulfite $(\sim 0.1 \mathrm{M})$ and at much lower optimum $\mathrm{pH}$ ( $\mathrm{pH} 4.0$ ) than the reversible addition of bisulfite to uracil and cytosine. ${ }^{12 e, 14 a}$ This is ascribable to the effect of the 5-carboxy group, which possesses $\mathrm{pKa}$ around 4 , thus increase in ionization should diminish considerably its electron-withdrawing property.

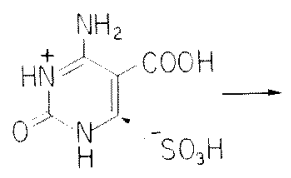

4

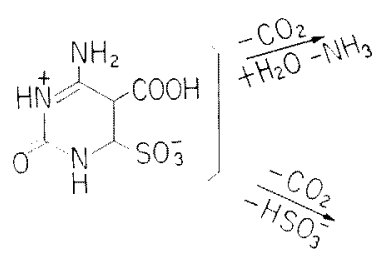

$$
\begin{aligned}
& +\mathrm{H}_{2} \mathrm{O} \\
& -\mathrm{NH}_{3}
\end{aligned}
$$<smiles>O=C1NC(=O)C(C(=O)O)C([SeH])[SeH]1</smiles>

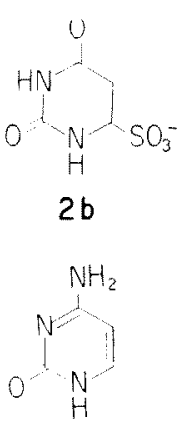

5<smiles>O=C1NCCC(Cl)N1</smiles>

Chart 2.

Analogous reaction was performed with 5-carboxycytosine (4). Reaction was found to be slower but here again a good yield of 5,6-dihydrouracil-6-sulfonate ( $2 b$ ) not the corresponding cytosine derivative was obtained beside small amount of uracil $(3 b)$ and cytosine (5). It is not unexpected since hydrolytic deamination of cytosine ${ }^{6 j}$ through intermediate addition at $\mathrm{C}-6$ with external nucleophile or more efficiently with intramolecular sugar hydroxyl of cytosine arabinonucleoside ${ }^{9}$. was well documented. Yield of cytosine in
There are several apparently analogous reactions reported, i.e., bisulfite mediated decarboxylation of 2-hydroxy-3-naphthoic acid, ${ }^{22}$ 3-carboxy - 5 - hydroxy - 7 -methylcoumarine, coumarine-3-carboxylic acid, ${ }^{24)}$ and 1-hydroxy2-naphthoic acid, ${ }^{25)}$ however, with no comprehension on reaction mechanism. These precedents are to imply the possible extension of the present reaction to the wide variety of compounds.

The successful application of this facile decarboxylation reaction to pyrimidine nucleo- 
side peptide antibiotics, polyoxins is described in the succeeding paper.

\section{EXPERIMENTAL}

Melting points were taken on a Yanagimoto micro melting point apparatus and are uncorrected. UV spectra were run on a Hitachi 124 spectrophotometer and IR spectra were run on a Perkin-Elmer 521 grating infrared spectrophotometer. Optical rotations were determined with a Perkin-Elemer 141 polarimeter. NMR spectra were run either on a JNM-C60 or on a Varian HA-100 NMR spectrophotometer. Chemical shifts were measured to internal DSS or TMS unless otherwise specified and recorded in ovalues. Coupling constants were expressed in $\mathrm{Hz}$. Thin-layer chromatography were carried out on Avical SF microcrystalline cellulose developed with $n$-butanol-acetic acid-water $(4: 1: 2)$. Heterocycles were detected under ultraviolet ray $(254 \mathrm{~m} \mu)$, sometimes after sprayed with $0.5 \mathrm{~N}$ $\mathrm{NaOH}$ solution and air-dried. Polyoxins were also detected by ninhydrin and periodate-benzidine reagents. For cellulose column chromatography, Avicel microcrystalline cellulose and for carbon chromatography, Chromatography Carboraffin (Takeda Chemical Industries Ltd.) were employed as adsorbent.

Reaction of polyoxin $\mathrm{C}$ acid (la) with $\mathrm{NaHSO}_{3}$. Polyoxin $\mathrm{C}$ acid ( $1 \mathrm{a}$ ), $510 \mathrm{mg}$, was dissolved in $15 \mathrm{ml}$ of $0.1 \mathrm{~N} \mathrm{NaOH}$ and $375 \mathrm{mg}$ of $\mathrm{NaHSO}_{3}$ dissolved in small amount of water was added. The solution was adjusted to $\mathrm{pH} 4.0$ with addition of $1 \mathrm{~N} \mathrm{HCl}$ and left to stand overnight in a $50^{\circ} \mathrm{C}$ bath. The reaction solution (final $\mathrm{pH} 4.0$ ) was concentrated to few $\mathrm{ml}$ in vacuo and applied to a carbon column $(35 \mathrm{ml})$. Elution was made first by water $(100 \mathrm{ml})$, then with $30 \%$ acetone $(50 \mathrm{ml})$. Among the fractions eluted with water, ninhydrin positive fractions were combined and concentrated in vacuo to dryness, yielding $270 \mathrm{mg}$ of white powder of $2 a$, mp $205 \sim 210^{\circ} \mathrm{C}$ (decomp.), $[a]_{0}^{25}-16.2^{\circ}$ $\left(c=1.266, \mathrm{H}_{2} \mathrm{O}\right)$. Calcd. for $\mathrm{C}_{10} \mathrm{H}_{15} \mathrm{~N}_{3} \mathrm{O}_{12} \mathrm{~S}: \mathrm{C}, 32.52$; $\mathrm{H}, 4.09 ; \mathrm{N}, 11.38 ; \mathrm{S}, 8.68$. Found: $\mathrm{C}, 32.55 ; \mathrm{H}$, $4.49 ; \mathrm{N}, 11.23 ; \mathrm{S}, 8.56$.

From the fractions eluted by $30 \%$ aqueous acetone, ninhydrin positive UV absorbing fractions were collected and concentrated in vacuo to dryness, affording $160 \mathrm{mg}$ of the residue, which was crystallized from aqueous ethanol to yield $95 \mathrm{mg}$ of colorless crystals, mp $240 \sim 245^{\circ} \mathrm{C}$ (decomp.), $[a]_{\mathrm{D}}^{25}+16.4^{\circ} \quad(c=0.205$, $\mathrm{H}_{2} \mathrm{O}$ ). IR spectrum in $\mathrm{KBr}$ was identical with uracil polyoxin C. Amorphous powder of $2 a$ (240 mg) from water eluate was chromatographed on a cellulose column with a solvent system of $n$-butanolaceticacid-water, changing stepwise from $(4: 1: 1.5)$ to $(4:$ 1:2). Eluate was collected in 11 fractions. Colorless amorphous substance obtained from each fraction by evaporation of solvent was measured its NMR and optical rotation. Substance from fraction 1 (epimer A): $15 \mathrm{mg},[\alpha]_{\mathrm{D}}^{25} \sim 32.8^{\circ}\left(c=0.500, \mathrm{H}_{2} \mathrm{O}\right)$, NMR ( $\mathrm{D}_{2} \mathrm{O}$, $100 \mathrm{~Hz}$, external TMS), 3.07, $3.31(2 \mathrm{H}$, ddd, AB part of $\left.\mathrm{ABX}, 5-\mathrm{CH}_{2}\right), 4.86(1 \mathrm{H}$, dd, X part of $\mathrm{ABX}, \mathrm{H}-6)$, $J_{5,5}=17.4, J_{5,6}=2.4,6.5,5.35\left(1 \mathrm{H}, \mathrm{d}, \mathrm{H}-1^{\prime}, J=3.2\right)$ (Fig. 4a). Substance from fraction 11 (epimer B): $16 \mathrm{mg}, \quad[\alpha]_{\mathrm{D}}^{20}+11.0^{\circ} \quad\left(c=0.516, \mathrm{H}_{2} \mathrm{O}\right) ; \mathrm{NMR} \quad\left(\mathrm{D}_{2} \mathrm{O}\right.$, $100 \mathrm{MHz}$, external TMS), 3.06, $3.34(2 \mathrm{H}$, ddd, AB part of $\left.\mathrm{ABX}, 5-\mathrm{CH}_{2}\right), 4.88(1 \mathrm{H}, \mathrm{dd}, \mathrm{X}$ part of $\mathrm{ABX}$, $\mathrm{H}-6), J_{5, \pi}=18.0, J_{5,6}=1.9,7.0,5.28\left(1 \mathrm{H}, \mathrm{d}, \mathrm{H}-1^{\prime}, J=\right.$ 2.8) (Fig. 4b).

Alkali treatment of $2 a$. Epimeric mixture of $2 a$ $(120 \mathrm{mg})$ was dissolved in $10 \mathrm{ml}$ of water. The resulting solution was brought to pH 12 with addition of $1 \mathrm{~N} \mathrm{NaOH}$ and warmed for $30 \mathrm{~min}$ in a $50 \mathrm{C}$ bath. The reaction solution was neutralized with $1 \mathrm{~N} \mathrm{HCl}$ and passed through a carbon column. After washed with water, the column was eluted with $30 \%$ aqueous acetone. From the UV-absorbing ninhydrin positive fractions $75 \mathrm{mg}$ of crystalline $3 a$ was obtained after recrystallization from aqueous ethanol.

\section{Reaction of 5-caboxy'uracil (lb) with NaHSO:}

Method A. 5-Carboxyuracil ${ }^{26}$ ( $\left./ b\right)(312 \mathrm{mg})$ was dissolved in $20 \mathrm{ml}$ of $0.1 \mathrm{~N} \mathrm{NaOH}$. To this, $624 \mathrm{mg}$ of $\mathrm{NaHSO}_{3}$ dissolved in small amount of water was added and $\mathrm{pH}$ was adjusted to 4.0 with $1 \mathrm{~N} \mathrm{HCl}$. The solution was placed in a $50 \mathrm{C}$ bath overnight. The reaction solution (final $\mathrm{pH} 3.1$ ) was passed through a carbon column, which was washed with water, then eluted with $10 \%$ aqueous acetone. From the eluate with water, fractions which absorbs UV light after sprayed with $0.5 \mathrm{~N} \mathrm{NaOH}$ on TLC were collected and concentrated to small volume, yielding $210 \mathrm{mg}$ of colorless crystals of 5,6-dihydrouracil-5-sulfonate $(2 b)$ as sodium salt monohydrate. It was recrystallized from water. It does not melt up to $300^{\circ} \mathrm{C}$, Anal. Calcd. for $\mathrm{C}_{4} \mathrm{H}_{7} \mathrm{~N}_{2} \mathrm{O}_{6} \mathrm{SNa}: \mathrm{C}, 19.92 ; \mathrm{H}, 2.93 ; \mathrm{N}, 11.62 ; \mathrm{S}$, 13.30; $\mathrm{Na}, 9.54$. Found: $\mathrm{C}, 20.39 ; \mathrm{H}, 2.96 ; \mathrm{N}, 11.76$; $\mathrm{S}, 13.34 ; \mathrm{Na}, 8.74$. NMR $\left(\mathrm{D}_{2} \mathrm{O}\right): 2.90,3.27(2 \mathrm{H}$, ddd, $\mathrm{AB}$ part of $\left.\mathrm{ABX}, 5-\mathrm{CH}_{2}\right), 4.54(1 \mathrm{H}, \mathrm{dd}, \mathrm{X}$ part of $\mathrm{ABX}$, H-6), $J_{5,5}=17.9, J_{5,6}=3.2,6.9$. Pyridinium salt of $2 b$ was prepared by passing the aqueous solution of $2 b$ through a Dowex 50w $(\mathrm{H})$ column. The eluate was directly received in a flask containing excess pyri- 
dine, which was concentrated in vacuo to dryness and the residual white poweder was dried over $\mathrm{H}_{2} \mathrm{SO}_{4}$ in a desicator. NMR (DMSO- $\left.\mathrm{d}_{6}\right): 2.75\left(2 \mathrm{H}, \mathrm{m}, 5-\mathrm{CH}_{2}\right)$, $3.91(1 \mathrm{H}, \mathrm{m}, \mathrm{H}-6), 8.97(\mathrm{IH}, \mathrm{d}, \mathrm{H}-1, J=5.5), 9.86(1 \mathrm{H}$, s, $\mathrm{H}-3)$.

From the eluate with $10 \%$ acetone from the carbon column, UV-absorbing fractions with identical $R f$ with uracil were collected and evaporated, affording $45 \mathrm{mg}$ of uracil. IR spectrum was identical with an authentic sample.

Method B. 5-Carboxyuracil (312 $\mathrm{mg}$ ) was suspended in $6 \mathrm{ml}$ of $1 \mathrm{M} \mathrm{NaHSO}_{3}$ (pH 4.2) and heated in a $65^{\circ} \mathrm{C}$ bath with occasional shaking. $\mathrm{CO}_{2}$ gas was evolved and after $20 \mathrm{~min}$ the solution was completed. During additional $40 \mathrm{~min}$ in a bath crystals were precipitated. After cooling crystals were collected by filtration, affording $350 \mathrm{mg}$ of $2 a$. Mother liquor was applied to a carbon column and eluted with $20 \%$ acetone, affording $20 \mathrm{mg}$ of uracil.

Reaction of 5-carboxy-2-thiouracil (lc) with $\mathrm{NaHSO}_{3}$. 5-Carboxy-2-thiouracil ${ }^{27}$ ( $1 \mathrm{c}$ ) $(328 \mathrm{mg}$ ) was reacted with $624 \mathrm{mg}$ of $\mathrm{NaHSO}_{3}$ in a similar way to the method $B$ in the preceding section. 5,6-Dihydro-2-thiouracil-6sulfonate (2c), $300 \mathrm{mg}$ was obtained as colorless crystals of sodium salt monohydrate. Anal. Calcd. for $\mathrm{C}_{4} \mathrm{H}_{7} \mathrm{~N}_{2} \mathrm{O}_{5} \mathrm{~S}_{2} \mathrm{Na}: \mathrm{C}, 19.20 ; \mathrm{H}, 2.82 ; \mathrm{N}, 11.20 ; \mathrm{S}, 25.63$; $\mathrm{Na}, 9.19$. Found: $\mathrm{C}, 19.43 ; \mathrm{H}, 2.98 ; \mathrm{N}, 11.17 ; \mathrm{S}, 24.44$; $\mathrm{Na}, 9.16$. NMR $\left(\mathrm{D}_{2} \mathrm{O}\right): 2.97,3.34(2 \mathrm{H}$, ddd, AB part of $\left.\mathrm{ABX}, 5-\mathrm{CH}_{2}\right), 4.68(1 \mathrm{H}$, dd, X part of $\mathrm{ABX}, \mathrm{H}-6)$, $J_{5,5}=17.8, J_{5,6}=2.6,6.8$.

Pyridinium salt was similarly prepared as preceding section, NMR (DMSO-d $\left.\mathrm{d}_{6}\right): 2.80\left(2 \mathrm{H}, \mathrm{m}, 5-\mathrm{CH}_{2}\right), 4.02$ $(1 \mathrm{H}, \mathrm{m}, \mathrm{H}-6), 9.72(1 \mathrm{H}, \mathrm{d}, \mathrm{H}-1, J=4.5), 10.77(1 \mathrm{H}, \mathrm{d}$, H-3).

Reaction of 5-carboxycytosine (4) with $\mathrm{NaHSO}_{3}$. Suspension of $933 \mathrm{mg}$ of 5-carboxycytosine $\mathrm{e}^{27}$ in $18 \mathrm{ml}$ of $1 \mathrm{M} \mathrm{NaHSO}_{3}$ was stirred in a $80^{\circ} \mathrm{C}$ bath for $3 \mathrm{hr}$. During that time, the solution was effected, then crystals were bigan to precipitate. After cooling crystals were collected, yielding $1.16 \mathrm{~g}$ of 5,6-dihydrouracil-6sulfonate (2b). Mother liquor was passed through a carbon column, which was eluted with $20 \%$ aqueous acetone. From the first UV-absorbing fraction, $10 \mathrm{mg}$ of uracil, and from the second fraction, $47 \mathrm{mg}$ of cytosine were obtained. Identification was accomplished on the basis of TLC and UV spectra.

\section{REFERENCES}

1) Studies on Polyoxins, Antifungal Antibiotics.
XV. For Part XVI, see reference 13 .

2) To whom correspondence may be addressed at the Institute of Physical and Chemical Research.

3) a) R. Shapiro and R. S. Klein, Biochem., 6, 3576 (1967); b) S. R. Heller, Biochem. Biophys. Res. Commun., 32, 998 (1968); c) R. J. Cashley, S. R. Lipsky and J. J. Fox, Tetrahedron Letters, 1968, 5393; d) W. J. Wechter, Collection Czech. Chem. Commun., 35, 2003 (1970); e) T. I. Kalman, Biochem., 13, 2567 (1971).

4) J. H. Phillips and D. M. Brown, Progr. Nucleic Acid. Res. Mol. Biol., 7, 349 (1967).

5) D. V. Santi and C. F. Brewer, J, Am. Chem. Soc., 90, 6236 (1968).

6) a) R. Shapiro and R. S. Klein, Biochem., 5, 2358 (1966); b) idem, ibid., 6, 3576 (1967); c) R. E. Notari, J. Pharm. Sci, 56, 804 (1967); d) W. J. Wechter and R. C. Kelly, Collection Czech. Chem. Commun., 35, 1991 (1970).

7) D. V. Santi and A. L. Pogolotti, Jr, J. Hetero. Chem., 8, 265 (1971).

8) a) J. J. Fox, N. C. Miller and T. J. Cashley, Tetrahedron Letters, 1966, 4927; b) B. A. Otter and J. J. Fox, J. Am. Chem. Soc., 89, 3663 (1967); c) B. A. Otter, E. A. Falco and J. J. Fox, J. Org. Chen.. 33, 3593 (1968); d) Idem, Tetrahedron Letters, 1968, 2967; e) Idem, J. Org. Chem., 34, 1390 (1969); f) D. Lipkin, C. Cori and M. Sano, Tetrahedron Letters, 1968, 5993.

9) R. E. Notari, M. L. Chin and A. Cardoni, Tetrahedron Letters, 1969, 3499.

10) a) B. Bannister and F. Kogan, J. Am. Chem. Soc., 82, 3363 (1969); b) R. W. Chambers and V. Kurkov, ibid., 85, 2160 (1963); c) E. J. Reist, A. Benitez and L. Goodman, J. Org. Chem., 29, 554 (1964).

11) K. Isono and T. Azuma, Chem. Pharm. Bull., 20, 193 (1972).

12) K. Isono, K. Asahi and S. Suzuki, J. Am. Chem. Soc., 91, 7490 (1969).

13) K. Isono, S. Suzuki, M. Tanaka, T. Nanbata and K. Shibuya, Tetrahedron Letters, 1970, 425.

14) a) R. Shapiro, R. E. Servis and M. Welcher, J. Am. Chem. Soc, 92, $422(1970)$; b) H. Hayatsu, Y. Wataya and K. Kai, J. Am. Chem. Soc., 92, 724 (1970); c) H. Hayatsu, Y. Wataya, K. Kai and S. Iida, Biochem., 14, 2858 (1970).

15) R. Shapiro and J. M. Weisgras, Biochem. Biophys. Res. Commun., 40, 839 (1970).

16) H. Hayatsu and M. Inoue, J. Am. Chem. Soc., 93, 2301 (1971).

17) a) P. Cerutti, K. Ikeda and B. Witkop, J. Am. 
Chem. Soc., 87, $2505(1965)$; b) P. Cerutti, Y. Kondo, W. R. Landies and B. Witkop, ibid., 90, $771(1968)$.

18) a) L. Czabo, T. I. Kalman and T.J. Bardos, J. Org. Chem., 35, $1434(1970)$; b) H. Inoue and T. Ueda, Chem. Pharm. Bull., 19, 1743 (1971).

19) a) H. U. Blank and J. J. Fox, J. Am. Chem. Soc., 90, $7175(1968) ; b$ ) H. U. Blank, I. Wempen and J. J. Fox, J. Org. Chem., 35, 1131 (1970).

20) R. L. Shriner and A. H. Land, J. Org. Chem., 6,888 (1941).

21) C. N. Caughlan and H. V. Tartar, J. Am. Chem. Soc., 63, 1265 (1941).
22) H. T. Bucherer, Z. Farb. Text, Chom., 1, 477 (1903); N. L. Drake, in "Organic Reactions," 1, 1942, p. 111.

23) R. Adams and J. Mathieu, J. Am. Chem. Soc., 70, 2120 (1948).

24) W. Daniewsky, Roczniki Chenii, 32, 667 (1958); [C. A., 53, 3201c].

25) N. N. Karandasheva and S. V. Bogdanov, Zhur. Obshchei Khim., 25, 1152 (1955); [C. A., 50, 3355f].

26) E. Ballard and T. B. Johnson, I. Am. Chem. Soc., 64, 794 (1942).

27) C. W. Whitehead and J. J. Traverso, ibid., 77, 5867 (1955). 